\title{
Case Report of Severe Preeclampsia and Associated Postpartum Complications
}

\author{
Pacarada M, Gashi AM*, Beha A and Obertinca B
}

Department of Obstetrics and Gynecology, University Clinical Centre of Kosovo, Pristine, Kosova

${ }^{*}$ Corresponding author: Gashi AM, Department of Obstetrics and Gynecology, University Clinical Centre of Kosovo, Pristine, Kosova, E-mail: astrit.m.gashi@hotmail.com

Citation: Pacarada M, Gashi AM, Beha A, Obertinca B (2016) Case Report of Severe Preeclampsia and Associated Postpartum Complications. J Case Rep Stud 4(4): 408. doi: 10.15744/2348-9820.4.408

Received Date: June 03, 2016 Accepted Date: August 29, 2016 Published Date: August 31, 2016

\begin{abstract}
Preeclampsia is clinically defined by hypertension and proteinuria, with or without pathologic edema that occurs after 20 weeks' gestation, but can also present up to 4-6 weeks post-partum. Worldwide, incidence of preeclampsia is 5-14 percent of all pregnancies, while severe preeclampsia can develop to about 25 percent of all cases of preeclampsia. Severe preeclampsia is a pathology characterized by endothelial dysfunction that can often be complicated, and thus may lead to liver and renal failure, disseminated intravascular coagulopathy (DIC), and central nervous system (CNS) abnormalities. Worldwide, preeclampsia and eclampsia is responsible for about 14 percent of maternal deaths per year. We present a case, from our clinic, which has had serious complications after birth and that ended with the death of the patient. Despite the adequate management with the timely diagnosis and therapy, patient died ten days after Caesarean delivery.
\end{abstract}

Keywords: Severe Preeclampsia; Postpartum; Complications

\section{Introduction}

Pre-eclampsia is clinically defined by hypertension and proteinuria, with or without pathological oedema that occurs after 20 weeks' gestation, but can also present up to 4-6 weeks post-partum [1].

Severe features of Preeclampsia include any of the following features;

(a) Systolic blood pressure of $160 \mathrm{~mm} \mathrm{Hg}$ or higher, or a diastolic blood pressure of $110 \mathrm{~mm} \mathrm{Hg}$ or higher on two occasions at least 4 hours apart while the patientis on bed rest

(unless antihypertensive therapy is initiated before this time).

(b) Thrombocytopenia (platelet count less than 100.000/microliter).

(c) Impaired liver function as indicated by abnormally elevated blood concentration of liver enzymes (to twice normal concentration), severe persistent right upper quadrant or [epigastric pain unresponsive to medication and not accounted by alternative diagnosis, or both.

(d) Progressive renal insufficiency (serum creatinine concentration greater than $1.1 \mathrm{mg} / \mathrm{dl}$ or a doubling of the serum creatinine concentration in the absence of other renal disease).

(e) Pulmonary edema.

(f) New-onset cerebral or visual disturbances.

Worldwide, incidence of pre-eclampsia is 5-14 percent of all pregnancies. In developing nations, incidence of pre-eclampsia is 4-18 percent [2,3]. Severe pre-eclampsia can develop to approximately 25 percent of all cases of pre-eclampsia [4]. Morbidity and mortality in pre-eclampsia and eclampsia are frequent. Severe pre-eclampsia may lead to liver and renal failure, disseminated intravascular coagulopathy (DIC), and central nervous system (CNS) abnormalities. In world, preeclampsia and eclampsia is responsible for approximately 14 percent of maternal deaths per year $(50,000-75,000)$ [5]. A woman with severe preeclampsia, and complicated with eclampsia or HELLP syndrome, has a 20\% risk of developing preeclampsia in her subsequent pregnancy [6-11].

\section{Case presentation}

A 34-year-old woman pregnant presented in Department of Obstetrics and Gynecology, University Clinical Centre of Kosovo, with 29 weeks'gestation and dyspnoea, expressed cyanosis, tachycardia, and epigastric pain. At the admission office, she had a blood pressure of 160/95 mmHg; pulse of 105 beats per minute, oxygen saturation was 96 . On physical examination, congenital deformity of the spine (kyphoscoliosis) was noticed. Skin and mucous membranes were pale. Data from the history show that the patient was treated by easy preeclampsia, from week 25 of gestation. Laboratory findings; hemograme was normal, 
urine analysis (protein 1+). Biochemical laboratory tests: serum aspartate aminotransaminase (AST), 67 IU/L; serum alanine aminotransaminase (ALT), $120 \mathrm{IU} / \mathrm{L}$; serum lactate dehydrogenase (LDH), $839 \mathrm{IU} / \mathrm{L}$; serum urea $10.74 \mathrm{mmol} / \mathrm{L}$ and $\mathrm{creatinine}$ was normal; Triglyceride, $3.49 \mathrm{mmol} / \mathrm{L}$; hemoglobin and platelet count were normal. Coagulation profile was normal. After consultations with a cardiologist, anesthesiologist and pulmonologist, patient was found to be having acute pulmonary edema. Ultrasound and Echocardiography revealed pericardial effusion, and other parameters anatomical structure of the heart were found normal. Chest x-ray, electrocardiogram and all necessary imaging examinations were also performed. Patient was transferred to intensive care unit, where she was intubated and connected to the respiratory apparatus. The ultimate diagnosis: 29 weeks pregnant, Preeclampsia, Pericardial effusion, pulmonary edema, Respiratory insufficiency, Kyphoscoliosis, Neurofibromatosis, Rh incompatibility (Patient a week earlier, at week 28 of gestation was treated with $300 \mathrm{mcg}$ of Rh IgG (RhoGAM), intramuscular injection). After stabilization of vital parameters for several hours, it was decided to terminate the pregnancy after a written consent of the patient. A Pfannenstiel incision was made and a female fetus was delivered weighing 1340 grams with APGAR score of 1 in the first minute and 3 in the fifth minute. The patient was treated with supplementary oxygen, crystalloid, antibiotics, H2blockers, LMWH, B-blockers, diuretic, analgesic, vitamin preparations, mucolytics, corticosteroids, anti-hypertensive and antiemetic. After a week of treatment in intensive care unit, the patient's condition improved, and therefore was extubated and shifted back to the Department of Obstetrics and Gynaecology under monitoring of cardiologist, anaesthesiologist and pulmonologist. After seven days, patient's condition rapidly deteriorated and went into cardiac arrest. Despite the resuscitation measures taken, it unfortunately ended up in her death after 10 days of cesarean delivery postpartum (exitus letalis).

\section{Discussion}

Preeclampsia is the disease of widespread vascular endothelial malfunction and generalized vasospasm. However, the pathophysiologic mechanism for preeclampsia is very complex. Severe preeclampsia can develop to approximately 25 percent of all cases of preeclampsia [4]. Worldwide, preeclampsia and eclampsia is responsible for approximately 14 percent of maternal deaths per year [5]. This disease may lead to liver and renal failure, disseminated intravascular coagulopathy (DIC), and central nervous system (CNS) abnormalities. Preeclampsia/eclampsia is one of the leading causes of maternal morbidity and mortality worldwide. Failure of clinicians to predict the impending life-threatening complications from preeclampsia may contribute to rise in maternal mortality due to this disease and its associated complications.

Early detection/diagnosis and appropriate management is extremely important in patients with preeclampsia, for better maternal as well as perinatal outcome.

Clinician must perform a detailed assessment along with thorough history taking (including the symptoms of severe preelampsia) and physical examination. Laboratory tests such as a complete blood count with platelet count, and assessment of serum creatinine and liver enzymes levels, evaluation for urine protein (24-hour collection or protein/creatinine ratio) may aid to establish the diagnosis. Fetal evaluation should be performed including antepartum fetal surveillance.

Precclampsia is a pregnancy-specific hypertensive disorder with multisystem involvement. Severe preeclampsia can result in both acute and long term complications for both the woman and her newborn. Maternal complications of severe preeclampsia include pulmonary edema, myocardial infarction, stroke, acute respiratory distress syndrome, coagulopathy, severe renal failure and retinal injury. These complications are more likely to occur in the presence of pre-existent medical disorders and with acute maternal organ dysfunction related to preeclampsia. Fetal and newborn complications of severe preeclampsia result from exposure to uteroplacental insufficiency or from preterm birth, or both. According to ACOG (2013), for women with severe preeclampsia at or beyond 34 0/7 weeks of gestation, and in those with unstable maternal-fetal conditions irrespective of gestational age, delivery soon after maternal stabilization is recommended.

\section{Conclusion}

This case report of patient who presented with 29 weeks of pregnancy, dyspnoea, expressed cyanosis, tachycardia, and epigastric pain to our clinical center. She developed complications associated with severe preeclampsia and unfortunately ended up with fatal outcome after 10 days of cesarean delivery post-partum, despite of timely diagnosis and adequate management.

Preeclampsia/ecclampsia is associated with substantial maternal complications, both acute and long-term. Clear protocols for early detection and management of hypertension in pregnancy at all levels of health care are required for better maternal as well as perinatal outcome.

\section{References}

1. Laganà AS, Favilli A, Triolo O, Granese R, Gerli S (2015) Early serum markers of pre-eclampsia: are we stepping forward? J Matern Fetal Neonatal Med 29: 3019-23.

2. Villar J, Betran AP, Gulmezoglu M (2001) Epidemiological basis for the planning of maternal health services. WHO/RHR.

3. Khedun SM, Moodley J, Naicker T, Maharaj B (1997) Drug management of hypertensive disorders of pregnancy. Pharmacol Ther 74: $221-58$.

4. Sibai BM (2004) Magnesium sulfate prophylaxis in preeclampsia: Lessons learned from recent trials. Am J Obstet Gynecol 190: 1520-6.

5. WHO (2004) The Global Burden of Disease, Geneva. 
6. Sibai BM, Ramadan MK, Chari RS, Friedman SA (1995) Pregnancies complicated by HELLP syndrome (hemolysis, elevated liver enzymes, and low platelets): subsequent pregnancy outcome and long-term prognosis. Am J Obstet Gynecol 172: 125-9.

7. Chames MC, Haddad B, Barton JR, Livingston JC, Sibai BM (2003) Subsequent pregnancy outcome in women with a history of HELLP syndrome at < or $=28$ weeks of gestation. Am J Obstet Gynecol 188: 1504-8.

8. Sibai BM, Sarinoglu C, Mercer BM (1992) Eclampsia. VII. Pregnancy outcome after eclampsia and long-term prognosis. Am J Obstet Gynecol 166 : 1757-63.

9. Lopez-Llera M, Hernandez Horta JL (1974) Pregnancy after eclampsia. Am J Obstet Gynecol 119: 193-8.

10. Adelusi B, Ojengbede OA (1986) Reproductive performance after eclampsia. Int J Gynaecol Obstet 24: 183-9.

11. Sibai BM, Mercer B, Sarinoglu C. Severe preeclampsia in the second trimester: recurrence risk and long-term prognosis. Am J Obstet Gynecol 165: 1408-12. 